\title{
Feasibility and Acceptability of the Mindfulness-Based OpenMind- Korea (OM-K) Preschool Program
}

\author{
Eunjin Kim (1) ${ }^{1} \cdot$ Monica M. Jackman ${ }^{2} \cdot$ Seong-Hun Jo ${ }^{1} \cdot$ Jisun $\mathrm{Oh}^{3} \cdot$ Shi-Yong Ko ${ }^{1} \cdot$ Carrie L. McPherson ${ }^{4}$. \\ Nirbhay N. Singh ${ }^{5}$
}

Published online: 1 June 2019

(c) The Author(s) 2019

\begin{abstract}
Objectives Preschool competency in self-awareness, self-management, social awareness, relationship skills, and responsible decision-making has been shown to affect short- and long-term social, emotional, and academic development. Known collectively as social emotional learning (SEL), these skills have begun to be paired with mindfulness-based programs (MBPs) in school settings. OpenMind (OM) is a newly developed mindfulness-based SEL program for preschool children. The aim of the present study was to evaluate the feasibility and acceptability of the OM program translated, culturally contextualized, and implemented as the OpenMind-Korea (OM-K) program in Korean preschools.

Method Eleven teachers in three preschools in Korea were taught the basic philosophy, principles, and nine activities in the OM-K program. The teachers implemented the OM-K program, together with the Nuri Curriculum that is mandated in all Korean preschools, with 1703 - to 5-year-old children. Following implementation for a school year, 10 of the 11 teachers completed 34-item feasibility and 8-item acceptability questionnaires. In addition, they were individually interviewed on their views regarding the OM-K program.

Results By the end of the year, each teacher was able to implement three or four activities of the OM-K program on a daily basis and the remaining activities as much as possible. The teachers were able to modify the activities to suit the children's needs and as afforded by the space available in each classroom. Overall the teachers reported that it was feasible to implement the OM-K program and that the program was acceptable to them. In addition, all teachers reported that they would recommend the program to other teachers.

Conclusions The OM-K program teachers in three Korean preschools rated the program as feasible and acceptable. However, there was some variation in the degree of feasibility and acceptability ratings across teachers within and between the three preschools. All teachers uniformly reported that they would recommend the program to other teachers because of its positive effects on both the teacher and their children. Program strengths and limitations are discussed and directions for future research are offered.
\end{abstract}

Keywords OpenMind $(\mathrm{OM})$ program $\cdot \mathrm{OM}-\mathrm{K}$ program $\cdot$ Social emotional learning $\cdot$ Mindfulness $\cdot$ Preschool

Eunjin Kim

ejkim2367@wku.ac.kr

1 Institute of Mind Humanities, Wonkwang University, Iksan, Republic of Korea

2 Little Lotus Therapy and Consulting, Port St. Lucie, FL, USA

3 University of Seoul, Seoul, Republic of Korea

4 McPherson Therapy and Consulting, Greenville, KY, USA

5 Department of Psychiatry and Health Behavior, Medical College of Georgia, Augusta University, Augusta, GA 30912, USA
There is increasing emphasis on self-regulation skills for children's school readiness and adjustment when transitioning from preschool to kindergarten (Pianta and Cox 1999). Children with good self-regulation skills are able to focus their attention during class, increase academic engagement by following teacher directions, and inhibit disruptive and aggressive behaviors at school (Blair and Diamond 2008). In addition, deficits in self-regulation skills often result in behavioral and social difficulties in preschool that may persist throughout the children's school years (Gerstein et al. 2011; Olson et al. 2005). Research suggests enhanced self-regulatory abilities in preschool may predict not only literacy and math achievement during grades $\mathrm{K}$ to 
12 but also college completion (McClelland et al. 2012). This suggests that preschool may be the critical period for intervention to decrease or preempt the development of behavioral and social difficulties of young children, given the key role of emotion regulation in reducing behavior problems (Kam et al. 2004).

Many interventions for increasing self-regulatory behaviors in preschool and $\mathrm{K}$ to 12 grades have largely been based on the Social Emotional Learning (SEL) framework as identified by the Collaborative for Academic, Social, and Emotional Learning (CASEL 2015). These interventions have focused on some or all of the domains or competency areas identified by CASEL, including selfawareness, self-management, social awareness, relationship skills, and responsible decision-making. Metaanalyses and general reviews of research on SEL have suggested that these domains are critical for promoting short- and long-term development of social, emotional, and academic skills of children (Durlak et al. 2011; Durlak et al. 2015; Taylor et al. 2017). However, programs directly or tangentially based on the SEL framework use various components and skills based on different theoretical constructs (Zins et al. 2004). For example, one of the early programs-Promoting Alternative Thinking Strategies (PATHS; Greenberg et al. 1995)_includes three key components: emotion identification, relaxation strategies, and perspective taking. The Social Decision Making/Problem Solving Program (Elias and Butler 2005), on the other hand, focuses chiefly on a number of social problem-solving strategies. In general, these programs are designed to improve students' emotional and behavioral skills, decrease mental health problems, and enhance academic performance. Meta-analyses show that these programs do indeed report great benefits for students in areas specifically targeted by such programs (Durlak et al. 2011; Sklad et al. 2012; Taylor et al. 2017).

In addition to SEL competencies, there has been an emerging interest in implementing mindfulness-based programs (MBPs) in schools (for reviews and applications, see Schonert-Reichl and Roeser 2016). Mindfulness has a long history as a meditation practice for awakening as in the Buddhist tradition (Shonin et al. 2015), but in the current context it has specific applications in enhancing academic, social, and mental health of students (e.g., Felver et al. 2016; McKeering and Hwang 2019; Zenner et al. 2014), as well as in teacher wellbeing (Hwang et al. 2017). Mindfulness has been defined as the "awareness that emerges through paying attention on purpose, in the present moment, and nonjudgmentally to the unfolding of experience moment by moment (Kabat-Zinn 2003, p. 145). MBPs in school settings have targeted a broad range of academic and psychosocial outcomes. For example, reviews indicate improvements in cognitive performance and resilience (Zenner et al. 2014), and reductions in behavior problems, improvements in mental health (e.g., anxiety, depression, and other affective disorders), and an increase in executive functioning (Felver et al. 2016). Given the complementary nature of SEL and current MBPs in education, a strong case can be advanced for integrating these two approaches (e.g., Gueldner and Feuerborn 2016; Lawlor 2016).

Several MBPs have been manualized and introduced in school settings. Examples include the Mind $U p$ program (Hawn Foundation 2011), Move into Learning (Klatt et al. 2013), and Learning to Breathe (Broderick 2013). However, these and similar programs were not explicitly intended to include the SEL competencies, although many do include one or more components. For example, in a major review of school-based MBPs that measured constructs which overlap with SEL competencies, Feuerborn and Gueldner (2019) reported that although none of the pertinent 40 studies reviewed included all five SEL competencies, all included one or more of these competencies. For example, all 40 studies included examples of self-management as an outcome variable. Of the selfmanagement variables, the most common exemplars included attention, concentration, positive and negative affect, various forms of anxiety, depression and sadness, and stress. Behavioral indices included anger, aggression, and problem behaviors as a general category. In terms of the other competencies, self-awareness and relationship skills were reasonably well represented but substantially less than self-management. Responsible decision-making and social awareness components were minimally represented in these studies. These findings suggest that if a transdisciplinary approach (Stokols 2006) to providing quality education that combines MBPs and SEL competencies is warranted, then new school-based programs should develop MBPs that explicitly include the five SEL competencies.

The aim of the present study is to assess the feasibility and acceptability of a MBP that was designed explicitly to include all five components of CASEL's (2015) SEL competencies. The OpenMind (OM) is a mindfulness-based SEL program for preschool 3- to 5-year-old children (Jackman 2016). The OM program is not intended to replace existing preschool curricula but to enhance the teachers' ability to provide quality preschool education that is informed by mindfulness practices, thus reducing stress for the teachers and increasing the children's SEL in preparation for $\mathrm{K}$ through 12 education. The present study provides initial data on feasibility and acceptability of the OM program based on a translated version of the program and culturally contextualized for Korean preschool children. 


\section{Method}

\section{Participants}

Teachers and 170 children from three preschools participated in the study. At each preschool, the classrooms were divided by age-3-year-olds, 4-year-olds, and 5-year-olds. One of the preschools had two classes for 3-year-olds, 1 for 4-year-olds, and 2 for 5-year-olds. The other two preschools had one class at each age level. In all, there were 11 classess (i.e., 4 for 3-year-olds, 3 for 4 -year-olds, and 4 for 5-yearolds) and 11 female teachers. The mean age of the teachers was 29.9 years (range $=25-40$ ). The average class size was 15.5 students (range $=13-20$ ).

\section{Procedure}

Local preschool principals were invited to implement a mindfulness-based SEL program in their preschools. Three preschools (Preschool A, B, and C) were selected to participate in this program. The parents and teachers at the three preschools were fully informed about the program and all provided written consent for participation. The Institutional Review Board at Wonkwang University provided ethical approval for the research component of the OM-K program.

The 11 preschool teachers received training in the principles and implementation of the OM-K program at a oneday (8-h) workshop provided by two trainers with expertise in this program. Training was provided prior to implementation of the OM-K program. Thereafter, every two weeks, the teachers received further training on implementing the OM-K daily activities from a Korean researcher trained in the OM-K program and were provided an opportunity to share their experiences with fellow teachers during the teacher education sessions. Additional training was provided periodically, as needed, by a university professor trained in the program.

\section{The OpenMind-Korea (OM-K) Program}

The OpenMind ("OM") is a mindfulness-based socialemotional learning program designed for teachers for use with 3- to 5-year-old English-speaking preschool children (Jackman 2016). A revised version of the OM program was translated into Korean and made culturally appropriate for Korean preschool children (Jackman et al. 2017). The Korean program, OpenMind-Korea ("OM-K"), includes nine daily practice activities that are integrated with the preschool's existing curriculum (i.e., Nuri Curriculum), with three activities (i.e., Samatha meditation, lovingkindness meditation, gratitude and interconnectedness practice) being used in the classroom on a daily basis and the remaining six activities (i.e., yoga, kindness and compassion reporting, feelings finder, super me, are you present for me?, soles of the little feet) used as needed. All activities are practiced daily as much as possible for noticing and reinforcing positive and prosocial behaviors. The nine daily activities include the five key SEL domains or competency areas as identified by CASEL (CASEL 2015). These domains include: self-awareness, self-management, social awareness, relationship skills, and responsible decision-making.

\section{Measures}

Two questionnaires were developed to assess the feasibility and acceptability of the OM-K program. At the end of the first year of implementing the OM-K program, the teachers completed both of these paper and pencil questionnaires independently. In addition, the teachers were interviewed individually to gather information on their personal observations regarding the $\mathrm{OM}-\mathrm{K}$ program and its implementation.

\section{Feasibility}

The feasibility questionnaire consisted of 34 questions that evaluated different aspects of implementing the OM-K program, including: meditation practice of the teachers; motivation to implement the program; issues regarding implementation of specific activities; barriers to implementation; integration of the OM-K program with the regular preschool curriculum (i.e., the Nuri Curriculum); risks and benefits of the program; and administrative support for the program.

\section{Acceptability}

The acceptability questionnaire consisted of eight items rated on a 5-point Likert scale: understanding the purpose and potential benefits of the OM-K program; ability to integrate the program with the preschool Nuri Curriculum; confidence in their ability to implement the program; beneficial effects for the children; change in the classroom environment; whether the teacher would recommend the program to other preschool teachers, effects of the meditation practice, and the teacher being more present in the classroom.

\section{Personal interviews}

The teachers were interviewed individually based on their responses to the two questionnaires to gather their personal observations regarding the program and its implementation. Depending on the teachers' responses, additional follow-up questions were included to get a more comprehensive understanding of their views. 


\section{Data Analyses}

Data were analyzed from only 10 of the 11 teachers who implemented the OM-K program because the eleventh teacher had taken a leave of absence due to pregnancy and childbirth prior to completing the questionnaires and personal interview. For the feasibility questionnaire, data were analyzed in terms of the teachers' response to each item, coded, and categorized together with the follow-up personal interviews. For the acceptability questionnaire, the rating choices ranged from "strongly disagree" (rated 1) to "neutral" (rated 3), to "strongly agree" (rated 5). The data were collapsed into three meaningful categories: disagree; neutral; and agree.

\section{Results}

\section{Feasibility}

The data are presented in terms of the content areas and summarized across the 10 teachers who completed the feasibility questionnaire.

\section{Meditation}

The OM-K is a mindfulness-based program that includes meditation as a prerequisite for its implementation. All 10 teachers reported that they had learned how to meditate as part of the OM-K program. In terms of average times across the school year, one teacher reported meditating $5 \mathrm{~min}$ a day, eight for $10 \mathrm{~min}$ a day, and one for $15 \mathrm{~min}$ a day. Seven teachers were aware of the importance of their meditation practice not only for themselves but also for the children. Thus, they meditated with the children each day both in the classroom as well as outside in the playground, weather permitting. Five teachers said that they could practice meditation much better by focusing on breathing. Before the $\mathrm{OM}-\mathrm{K}$, they thought that posture was important, so they focused on having a good posture but could not practice meditation properly. After the OM-K meditation training, they learned that it was important to pay more attention to the breath rather than posture, so they were able to practice meditation easily and comfortably by following the flow of the breath.

Since meditation time is a time for me, I practiced meditation together after I gave the children enough explanation. When I was in preschool, I had a routine to interact with children all day long, then there is a time when the teacher becomes mentally distressed. There is a time when the teacher constantly observes that the children fight and argue with each other, since [we have had] meditation time, the short meditation time, which is 10 min long is very helpful to the teacher. Because the classrooms for 3-yearold children and older have no time for a nap, there is no quiet time except for cleaning time, so it is important to have meditation time for teachers and children. When it is a tough day and I do not have much meditation time, when the kids go home, I sit at the teacher's desk and practice meditation alone for a while before cleaning my classroom. (Teacher for 4-year-olds, Preschool C)

Before I was trained in the OM-K program, I thought meditation was difficult and hard to practice and I did not think about trying it. However, through OM-K training, I use it in my daily life knowing that a trivial thing from breathing lightly to feeling one's whole body can be meditation. For example, living with children can make me both angry and painful, and I cannot express my feelings directly to the children, but hiding them does not make negative emotions disappear. In that case, I usually solved the problem by sighing in frustration, but through OM-K I thought that it would be better to breathe rather than to heave a sigh, so after I breathe for a moment and meditate, I can talk to the children comfortably. Breathing-oriented meditation seems to be the easiest way to be mindful in everyday life. From time to time, I practice meditation by myself in my daily life by being aware of the flow of my breath, regardless of whether the children are present or not. Also, I thought that I should set an example for the children, so I was be able to concentrate more on meditation during the guided meditation time with the children. (Teacher for 5year-olds, Preschool B)

If the teachers were unable to meditate at the preschool, the reasons for this included outdoor events (six teachers), playful children (three teachers), school drop-off time (two teachers), and noisy classroom environment (one teacher). The teachers were unable to meditate on days when an outdoor program was scheduled because the children engaged in a different morning routine before they boarded the bus for the outdoor activity. The teachers noted that while they could arbitrarily adjust the time of regular classroom activities, they could not do so for outdoor activities because cooperation of many people was required, including that of the bus driver. Also, the teachers reported that it was hard to practice meditation when playful children were disruptive. In addition, because meditation was usually scheduled in the morning, class meditation had to be stopped sometimes when children arrived at the preschool at different times, requiring the teacher to greet the children as they arrived.

The teachers used a number of strategies to enhance daily meditation practices, including setting a fixed time for meditation (four teachers), assistive tools, such as use of the meditation bell (four teachers), and paying attention to the breath (two teachers). Other factors that helped maintain meditation practice included children who performed well 
(one teacher), the praise and encouragement by the researchers (one teacher), and the general atmosphere of the preschool that emphasized character education rather than academics (one teacher). Furthermore, the school-wide guided meditation broadcast at 10:00 am was helpful in implementing meditation practice each school day. Additional meditation techniques (such as focusing attention on the flow of the breath during inhalation and exhalation) and accessories (such as use of the Hoberman ball and the meditation bell) enabled the teachers and children to practice meditation more easily.

The preschool set the meditation time and broadcasted the guided meditation, so I was able to connect with other meditations in addition to the guided meditation at that time. (Teacher for 3-year-olds, Preschool B)

We used to practice sitting meditation in preschool every day, but there were new methods in OM-K, such as the Hoberman ball and Lotus Breathing, so we could learn and practice meditation happily along with the children. In fact, when it comes to meditation, we used to focused on "make your posture upright", "close your eyes" and so on, but OM-K puts emphasis on breathing, feeling the flow of the breath. It was easy to explain and demonstrate to the children and they were able to follow this instruction very well. (Teacher for 4-year-olds, Preschool A)

At the preschool level, the school-wide broadcast indicated that it was time for the children to meditate, so naturally it became a habit for adjusting the posture and attitude for meditation. Also, various meditation tools such as the meditation bell and Hoberman ball were offered and utilized so that meditation could be conducted in a class format. (Teacher for 5-year-olds, Preschool B)

\section{Motivation}

Eight teachers were highly motivated to implement the OM$\mathrm{K}$ program in their classrooms after receiving training. Reasons for this included being interested in the OM-K activities (four teachers), confident about using the new materials (two teachers), liked the new meditation technique (one teacher), and applicability in daily classroom routine (one teacher). The remaining two teachers had a somewhat negative attitude toward implementing the OM-K program because of questions regarding how to integrate the new activities within the Nuri Curriculum given the educational demands of parents, and the diverse range of activities already prescribed in the curriculum. Similarly, after receiving the OM-K training, eight teachers were positive about whether they thought they would be able to implement the OM-K program, and two teachers expressed a sense of burden. The reason the 8 teachers thought they could incorporate it was because there was a teacher manual (three teachers), the program used interesting and easy tools (three teachers), and did not seem too difficult to incorporate with the Nuri Curriculum (two teachers). However, the two teachers who assumed it would be difficult to incorporate the nine additional activities each day believed that they had not mastered the OM-K activities prior to being asked to implement the program.

\section{Implementation}

Teachers responded that they could include three or four activities (six teachers), five activities (three teachers), and six or seven activities (one teacher) out of the nine daily activities each day. The teachers engaged in and assisted their students to meditate each school day. In addition, they engaged in several daily activities or variants of the remaining eight key OM-K activities, including Attention to the Sound of the Bell (five teachers), Lovingkindness Meditation (four teachers), Yoga (four teachers), Feelings Finder Board activity (three teachers), Gratitude and Interconnectedness Practice (three teachers), Hoberman Breathing (three teachers), Super Me Board activity (two teachers), Kindness and Compassion Reporting (one teacher), Birdie Breathing Song (one teacher), and Walking Meditation (one teacher). The teachers reported finding the daily meditation to be the easiest activity to perform. One of them responded, "Because I can start [it] with just my mind, without any special tools and preparation," and two other teachers said that because the meditation instruction was [audio] broadcasted at the preschool level every morning, they were getting used to doing it and were able to do it without difficulty. Also, the teachers noted that the children were interested in tools and activities like the Hoberman Breathing Ball (three teachers), attention to the sound of the Bell (two teachers), Yoga, Lovingkindness Meditation, Birdie Breathing Song, and Feelings Finder Board (one teacher).

Some teachers (six teachers) found yoga to be the most challenging activity to incorporate in their classrooms. This was not due to the activity itself, but because the limited space available in each classroom made it difficult for the children to practice the yoga postures. Other activities that were challenging included the Super Me Board and Feelings Finder Board activities because the need to use them could arise across different situations where it was inconvenient or the tool could not be easily accessed when needed (two teachers). The Soles of the Little Feet and Are You Present for Me activities did not translate well culturally in the Korean context and one teacher found them difficult to implement.

In terms of practicality of the OM-K activities, five teachers used them often, three moderately, and two found them somewhat difficult. The teachers who reported using the activities frequently tried to integrate at least some 
activities within the general curriculum even if they could not integrate the activities well. The teachers who had difficulty in integrating the OM-K activities reported that it was difficult to combine them with the daily routines of the preschool. With reference to modifying the activities to suit their children and classroom environment, nine teachers were able to do this, with the remaining teacher opting to use the activities as presented in the OM-K training manual.

Because the classroom and the restroom are separated, it can get crowded if they go to the restroom as a group. So, I let the children go to the bathroom individually by sending children who used different OM-K activities to manage their behavior, such as a child who preferred to use a Hoberman Breathing ball. In addition, children liked animals and wanted to imitate them, so from the lion posture [in yoga] I could make various yoga postures such as tiger, crocodile, and bear for the children to use while waiting for their turn. (Teacher for 3-year-olds, Preschool A)

The children benefitted when I was able to modify the $\mathrm{OM}-\mathrm{K}$ activities to suit my students. I was not only able to work on and plan the activities, but I was also able to modify the existing programs and add activities to them because the children gave me good ideas regarding their feelings from participating in the Feelings Finder Board activity. When it came to using the Gratitude Flowers, the children freely transformed the flowers with colored paper, and on Super Me Board they used it first. In addition to the formal morning meditation sessions, my class was able to practice meditation outdoors (e.g., in the playground) as well. If it was sunny, we could go outside and meditate on the sound of nature. (Teacher for 4-year-olds, Preschool C)

With regard to the question, "If changes could be made to the OM-K program to make it more feasible to implement it in your classroom, what changes would you suggest?", four teachers had no suggestions for change or additions to the current program, but the other teachers suggested the development of a weekly educational plan (two teachers), development of a practical educational plan based on specific examples (two teachers), and the development of additional variations of the activities (one teacher). Their responses were in the context of classroom applications rather than the OM-K program itself. For example, one teacher suggested: "It would be better to have a more systematic plan like an annual curriculum, a monthly curriculum, and a weekly curriculum, rather than leaving them at the [OM-K] teachers' discretion." Several teachers preferred carrying out chosen activities at a specific time rather than to integrate the OM-K activities within the preschool curriculum.

In response to the question, "By the end of the school year if you were able to successfully implement the OM-K Curriculum in your classroom, what helped you to do it?", the teachers provided multiple applicable answers as follows: witnessing positive change in the children (four teachers), encouragement by researchers (three teachers), regular teacher education (two teachers), meditation at a fixed time (one teacher), preschool's education policy (one teacher), teacher's own awareness of the necessity of meditation (one teacher), and teacher's decision not to stop implementing the program (one teacher). The teachers said that the change in the children encouraged them to do it for a year, although they were not sure that some of the children were making progress. The teachers noted that they were able to continue with the OM-K program because they saw significant changes in the children. In addition, they noted that even if they had doubts ("Is this right?") while implementing the program, the praise and encouragement by the researchers provided great strength and motivation for the teachers.

Initially, the program was operated under the teacher's supervision, and at some point, the children tried to solve their problems themselves (such as using Feelings Finder Board when they were emotionally upset). In my class, children use the Feelings Finder Board a lot. Initially, when the children were fighting, I showed them how to use the Feelings Finder Board. Later, I sometimes saw how two children would sit down and use the Feelings Finder Board to talk about what happened in the morning and attach the emotion keys to the board. So, I thought, "Oh, this has become a tool that the children can use on their own." In addition, when a child is emotional, sometimes a friend gives the Hoberman ball to him/her, saying, "Try this", which enables the upset child to calm down. Also, I posted Birdie Breathing Song lyrics on the wall and, upon seeing it, some children sat down and did some of the movements. Looking at these changes in the children, I was able to be with children in a stable and centered manner. (Teacher for 5-year-olds, Preschool A)

It was a great help because there was a researcher who visits [the preschool]. When my mind was unsettled, the visit awakened me with "Oh, this should be done." Also, I was able to tackle the programs specifically with teacher education every two weeks. While asking questions and communicating, the program was much easier to proceed as the teacher [i.e., trainer from the University] deepened my understanding of a particular program. I think the most important thing is how much the teacher understands the program. (Teacher for 5-year-olds, Preschool B)

I did not do many activities, but I worked hard with the Samatha meditation. The reason is I felt that I needed this activity and the children kept following it. (Teacher for 5year-olds, Preschool C)

\section{Barriers to implementation}

The teachers provided a range of answers to the question, "By the end of the school year, when you were not able to 
successfully implement the OM-K Curriculum in your classroom, what hindered you from doing it?". The teachers noted academic pressure of the Nuri Curriculum (three teachers), unfocused children (three teachers), outdoor programs (two teachers), teacher's lack of competence (one teacher), and no answer (one teacher). As a result of asking additional questions about what the most disruptive factor was, four teachers emphasized the time needed to implement the Nuri Curriculum. Two other teachers noted that they have to show the results of using the Nuri Curriculum through completed worksheets of educational materials such as psychology art, play materials, and Korean language textbook. In addition, because they have to send these worksheets home with the children, they need to give priority to the Nuri Curriculum. Given the reality of the Korean education system that is heavily focused on academic achievement, parents are more interested in academic learning outcomes than in the SEL emphasized by the OM$\mathrm{K}$ program.

Because it is a class for preschool children which uses the Nuri Curriculum, at times it was difficult to implement the OM-K activities in such areas as science activities and story-telling within the given time limit. (Teacher for 3year-olds, Preschool A)

There was a specific daily routine so implementing OM$\mathrm{K}$ was difficult because it was in addition to the Nuri Curriculum. There were many things, such as field trips and other events, so it was hard to find extra time for OM-K. I have been working on the program for a year, but I think I could have done better if I had to spend more time on OM$\mathrm{K}$ and reduce Nuri Curriculum, which should show in the results. At preschool level, I had to follow a private program tailored to Nuri Curriculum, which included daily basis activities such as science experiments, reading selected books [to the children], and linguistic activities. We needed outcomes from these activities to send home with each child. Because I had to do these things, I could not spend much time on the OM-K program. (Teacher for 3-year-olds, Preschool B)

I teach children who are five years old, I had to focus on academic learning so it seemed that I could not afford to do anything else. As the second semester began, it seemed that there were lots of things for the children to learn before entering the school so I had a lot of things to do and could not afford the time to do it. (Teacher for 5-year-olds, Preschool C)

In terms of what they did to overcome these barriers, the teachers indicated that they made an effort to somehow overcome them. In addition, one teacher said that "there were no barriers" and another noted that "OM-K could not be used with the outdoor programs". The other eight who made an effort to solve these problems offered the following responses: "Although there was a burden due to the Nuri
Curriculum, while using meditation, yoga, and so on with the classroom activities, I could sense a change in the classroom atmosphere" (three teachers). "Even though [I was] burdened by overwork and time constraints, I tried to do it by myself as their teacher" (three teachers). "As I watched the children changing little by little, I saw for myself the necessity of this program" (one teacher). "At the end of the large group period, I added OM-K activities" (one teacher). Although the teachers' responses varied, all were aware of the necessity for this program, and it motivated them to overcome the obstacles.

\section{Integration}

The teachers' answers to the question "Were you able to integrate the OM-K Curriculum with your standard (Nuri) curriculum?" were generally "yes" (seven teachers). Of the remaining three teachers, one was neutral and the final two teachers said "no". Factors that helped overcome the difficulty of integrating the OM-K program with the Nuri Curriculum included: "Because there was a designated meditation time, I was able to engage in OM-K activities even for short periods"(two teachers); "setting up Mindfulness Area" (two teachers), "implemented easy and simple activities like bell or Feelings Finder Board" (two teachers), "regular teacher education and researcher's observation" (one teacher), "continuous study of the OM-K manual" (one teacher), and "a combination of approaches," (one teacher). The teachers used many different ways to incorporate the OM-K activities despite obstacles, such as lack of time, a focus on academic learning, and so on.

For example, when dealing with the topic of our neighborhood, I was able to combine Gratitude and Interconnectedness Practice as we found out our neighbors who helped us, and I tried bell activity and yoga posture as a transition between activities. (Teacher 1 for 3-year-olds, Preschool A)

There are activities in the OM-K program that can be combined by theme, so I tried to combine and implement them. For example, when we were learning about me and my family, I tried to express a heart of gratitude through Lovingkindness Meditation, and when we were learning about our neighborhood, I was able to do Kindness and Compassion Reporting. (Teacher 2 for 3-year-olds, Preschool A)

Rather than fully integrating the OM-K program into the Nuri Curriculum, the programs were introduced to children in small and large activities, such as leaving the building, language, art, and role-play activities in the weekly plan, and then I allowed the children to use them by themselves during free playtime. That is one of the reasons why I set aside the mindfulness area. (Teacher for 3-year-olds, Preschool C) 
In general, OM-K materials were kept in the free choice activity area to be used by the children, except that OM-K activities were introduced for a short period of $10 \mathrm{~min}$ after meditation. Although I felt that the burden of having to take extra time to do the nine activities in the first OM-K workshop, when I actually tried it, it seemed that I could proceed with interacting with the children in daily life without taking time separately. (Teacher for 4-year-olds, Preschool B)

The manual was very helpful. I kept it in the classroom so that I could study and grasp its core activities. During the large group activities in Nuri Curriculum, I used it in the form of a supplement. I think the teacher should continue to study the OM-K manual. (Teacher for 4-year-olds, Preschool C)

\section{Risks and benefits of using the OM-K program}

The teachers were asked if they perceived any risks to the children due to participating in the OM-K program, all but two teachers responded that they did not. These two teachers assumed that the children could hurt themselves if they dropped the bell, so they did not let the children touch it (two teachers). With respect to the benefits of the OM-K program, most teachers had similar responses. They noted that the program resulted in stability of mind (seven teachers), increased expression of emotions (eight teachers), improvement in emotion recognition (three teachers), and enhanced good behavior (two teachers).

Typically it was difficult for the children to express their emotions, but they learned to express them in various ways through the OM-K activities, and they were able to adjust their emotions in difficult situations by activitly working on their minds. I could see that the playful children became calmer as they practiced meditation and when a child cried, other friends came and told the child to "breathe". Another example, would be if a friend did not share a toy, the other child who was upset would bring the Feelings Finder Board and express his or her emotions by attaching two sad expression keys on the board. (Teacher for 3-year-olds, Preschool C)

When the children's emotions became very strong while playing, the mind was stabilized by the meditation, and it was found to become a little easier for the children to know and express their mind through the Feelings Finder Board. Before that, the children did not reveal their mind well. When I let them watch the emotion cards and express their minds along with them, at first, they were too shy to speak their minds well. Now, they naturally say, "Teacher, today I felt this way because of this," and they expressed their emotions with friends and they, who could not have said "I am sorry," before, said "I am sorry" and the other(s) respond saying "It is okay." In this way, I could see that they were changing because they could read others' emotions. (Teacher for 4-year-olds, Preschool A)

I saw that a child meditated on his or her own when he or she was not psychologically stable. Also, there was an unfocused boy, and his mother said that he was breathing at home when he was upset. I saw that he was breathing by himself at the classroom as well when he was upset. (Teacher for 5-year-olds, Preschool C)

\section{Administrative support}

All of the teachers responded positively when asked about how much support they received from their preschool to implement the OM-K program. They noted that participation and encouragement by the researchers (six teachers), regular teacher education (2 teachers), and teachers' workshop (one teacher) were the biggest supports, indicating that emotional support and encouragement rather than any material support was what the teachers found most useful. They reported that their interactions with the researchers were very positive and they gained courage from their praise and encouragement to implement the OM-K program very comfortably. The teachers responded that they were provided with enough resources by the administration, including the bell (four teachers), Hoberman breathing ball (one teacher), the two Boards (one teacher), pictures of yoga poses (one teacher), various OM-K program materials (one teacher), and preschool principal's direction (one teacher). The OM-K program materials were very helpful in implementing the program and, in particular, both teachers and children used the bell. Also, one teacher mentioned the direction of the preschool's principal as the most helpful resource for OM-K implementation, and she said that the principal and the preschool's atmosphere emphasized character education so she could grant priority to $\mathrm{OM}-\mathrm{K}$ program activities.

The most helpful thing was the bell. At first, when the children were concentrating on their activities, they did not recognize the sound of the bell. When they heard the bell, they just lowered their hands rather than lowering their hands after the sound ended. However, after a while, the children heard the bell sound to the end, and then lowered their hands. They were concentrating on the sound. (Teacher for 4-year-olds, Preschool A)

OM-K is a program that the preschool considers to be a priority so I could implement it. When it was first started, the principal did not know about what OM-K program is, but the researchers continuously visited, talked, and praised the teachers, who were doing well with OM-K program activities, so the principal began to take an interest in it as well. Also, the preschool seems to have a good fit with OM$\mathrm{K}$ program because it places a high value on [children's] 
character and more focused on activities in nature. (Teacher for 4-year-old, Preschool C)

\section{Acceptability}

The teachers' acceptability ratings are presented in Fig. 1. The ratings show that all 10 teachers fully understood the purpose and potential benefits of OM-K daily activities. While no teachers rated being confident of their ability to implement the program activities, seven of the 10 teachers were able to integrate the OM-K program within the classroom activities, i.e. with the Nuri curriculum. Similarly, seven of the 10 teachers responded that the OM-K program was beneficial for their children, and eight of the 10 teachers noted that it helped to create a more peaceful classroom environment. All teachers responded that they would recommend the OM-K program to the other preschools or teachers, suggesting they saw a positive effect of the program on the children. Similarly, seven of the 10 teachers noted positive effects of the meditation, and all 10 teachers stated that the OM-K program enabled them to be more present for the children in their classroom.
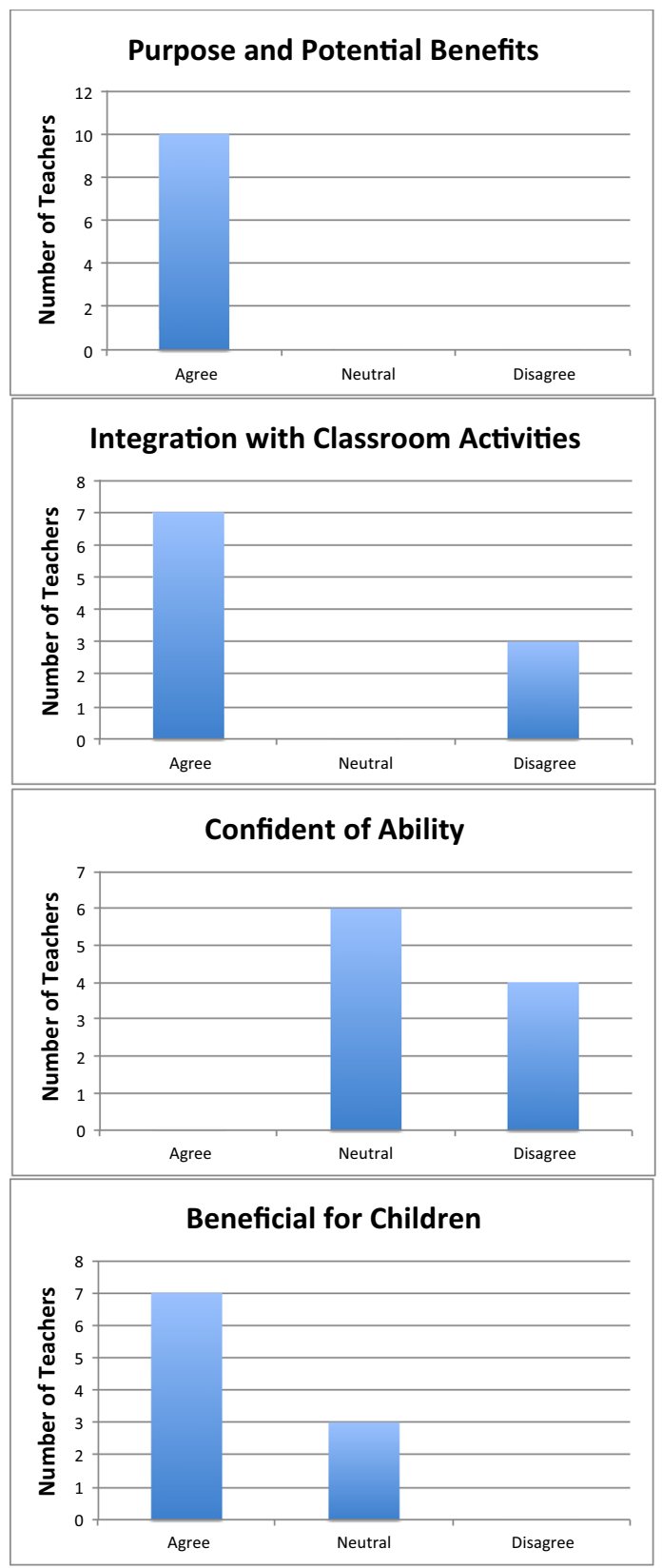

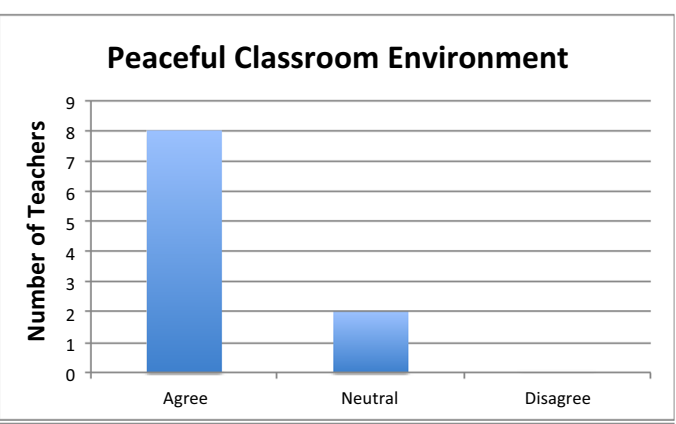

Recommend to Other Teachers
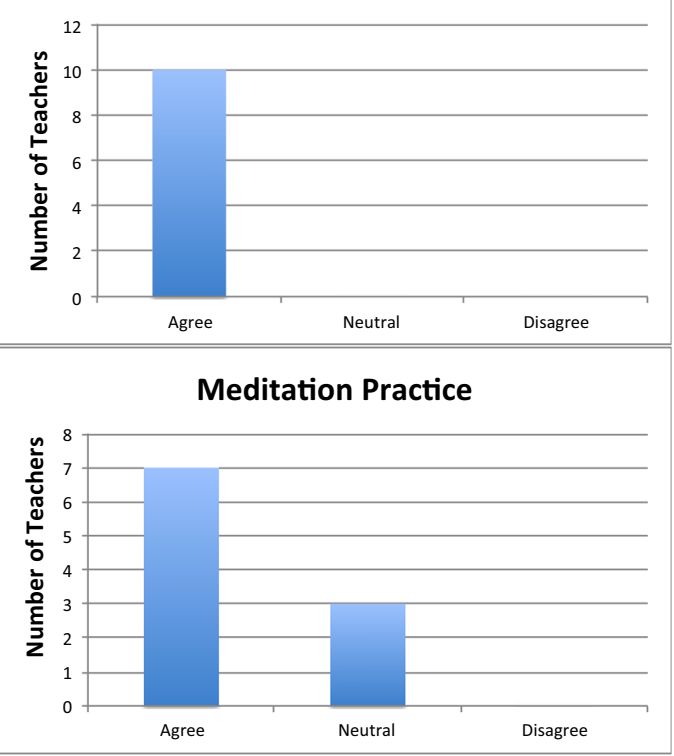

More Present for My Classroom

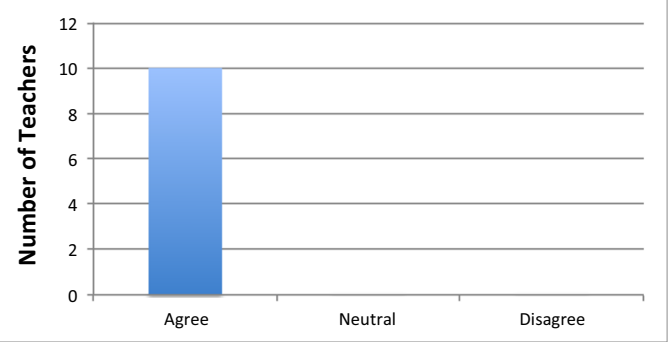

Fig. 1 Teacher ratings of acceptability of the OM-K program 


\section{Discussion}

This study investigated whether implementation of the OM$\mathrm{K}$, a mindfulness-based SEL program for preschool children, was feasible and acceptable to Korean teachers and preschool children. The OM-K is not a preschool curriculum but a mindfulness-based program that is used together with the standard Nuri Curriculum prescribed for all Korean preschools. The key issue for the teachers in implementing the OM-K program was whether they could incorporate the program activities within the Nuri Curriculum. OM-K was designed to enable the teachers to use the activities in the context of the classroom rhythm of life, i.e., during play, academic lessons, transitions, and self-care activities such as eating and rest. The term rhythm of life refers to the use of activities in the naturalistic context of daily life when the need or opportunity for a learning experience occurs. For example, a teacher may introduce discussion of emotions and behavioral choices of characters during reading of a book to encourage lovingkindness practice and nonjudgmental acceptance if she observes a child is being excluded by peers because he may look different or engages in unique behaviors.

Following training in the OM-K program activities, the teachers found the program to be interesting, the manual useful, and the activity materials interesting and easy to use. In fact, the teachers indicated that they were able to implement three or four activities following the initial training and continued using them throughout the year. The teachers found the activities fairly practical, and most were able to implement each activity in their classrooms. Given familiarity with the activities, the teachers were able to customize the activities to suit the developmental and cultural context of the children. All teachers were able to guide their children in the daily meditations, an activity that they reported to be the easiest to implement. Assisting the children to meditate was made easier by having a guided meditation broadcast throughout the preschool at a regular time each day. Furthermore, unlike previous attempts which emphasized sitting meditation posture, the emphasis in this program on simply following the flow of the breath made it much easier for the teachers and their children to meditate.

In terms of acceptability of the OM-K program, all teachers were positive about its purpose and benefits. Most reported beneficial effects of the program, producing general calmness in the classrooms, without any risks to the children. All teachers uniformly reported that they would recommend the program to other teachers because of its positive effects on both the teacher and their children. Although there was variation across teachers, generally the teachers reported that implementation of the program was feasible and acceptable to them.

\section{Strengths and Limitations}

The OM-K program is unique in several respects. First, it was developed to integrate a specific MBP with SEL competencies, a noted deficit in school-based MBPs. The program activities develop and/or strengthen the five SEL competencies-self-awareness, self-management, social awareness, relationship skills, and responsible decisionmaking. Second, the program includes a customized schoolwide guided meditation that is broadcast daily at a specific time, thus enabling the teachers and children to anticipate it as a part of their daily routine. Consequently, the children were able to meditate regularly on school days as a part of their morning activities, setting up the context for positive interactions and learning during the rest of the day. Daily practice of meditation and the other OM-K activities helps to create positive habits and build self-regulation and executive function skills in the children.

Third, the use of various visual aids that made the children more mindful made implementing the program easier for the teachers. Examples of these aids include the "Hoberman breathing ball" for helping the children to breathe, the "Gratitude Flowers" for encouraging the children to express their appreciation, the "Super Me Board' for strengthening peer interactions and friendly behaviors, and the "Bell" for focusing attention. The provision of audiovisual materials at developmentally appropriate levels for 3 to 5-year-olds added to the ease of implementing the program activities.

Fourth, the OM-K program integrates mindfulness activities into the daily preschool curriculum and has complementary principles that can improve mindfulness in both teachers and children. Although the teachers were initially responsible for implementing the program, gradually the children began using some program aids (e.g., the Hoberman Breathing Ball, the Feelings Finder Board) without teacher directions. At this stage of implementing the program, the teachers realized that this provided them with an opportunity to practice meditation for their own benefit instead of focusing solely on teaching the children how to meditate. We suspect the meditation aspect of the OM-K program appears to encourage the development of mindfulness in both teachers and children.

The results are not without limitations. Although, by the end of the year, a majority of the teachers were able to use 4 or 5 OM-K activities every day in their daily routine, some teachers had difficulty in integrating the activities due to the diverse daily routine of the preschool. In particular, the Nuri Curriculum, a standardized national curriculum for Korean children aged 3- to 5-years required a substantial investment of the teachers' time because expected academic outcomes had to be met regardless of the addition of the OM-K program activities. While this may not be a problem in western 
countries that emphasize SEL more so than academic outcomes in their preschools, the Korean educational system is very sensitive to academic achievement. Therefore, the OM-K program activities may need to be contextualized better for the Korean educational system by providing the teachers with a plan for systematic implementation throughout the day. Giving the teachers the option of using program activities as the need arises may not be an optimal implementation plan. For example, the OM-K program provides flexibility for the teacher but in order to help teachers in Korean preschools to integrate more program activities into their daily curriculum, alternatives linked to weekly or monthly education plans may be needed. Future research needs to assess how OM-K program activities can be incorporated into the Nuri Curriculum.

Another consideration arising from this study is the role of the preschool principal in implementing the OM-K program. For example, the principal sets the tone for implementing new programs. If the principal emphasizes mindfulness of the children as a priority, the teachers invariably follow the lead of the principal and do their utmost to implement the program. Another consideration is that university-based researchers may need to increase their presence in the preschools when a new program is introduced, thereby providing support to the principal, teachers, and parents through frequent interactions, information about the new program, instruction on the components of the program, and positive reinforcement for each successive step in the implementation of the program. Furthermore, by increased presence in the early stages of implementing a new program, such as OM-K, researchers can collaborate with the principal, teachers, and parents in solving problems as they arise, modify the program components to fit the needs of the teachers and children, and provide social support.

Funding Information Preparation of this research was supported by a National Research Foundation of Korea (NRF) grant (NRF-2010-361A00008) funded by the Korean Government (MEST).

Author Contributions EK designed and executed the study, analyzed the data, and wrote the paper; MMJ developed the OM program; SJ translated the $\mathrm{OM}$ program into Korean and collaborated in its implementation; JO collaborated in the implementation of the program; SK enabled the implementation of the OM-K program and provided research support; CLM provided initial training on the OM-K program to the teachers; and NNS collaborated in all phases of the study.

\section{Compliance with Ethical Standards}

Conflict of Interest MMJ is the developer of the OM program. The remaining authors declare that they have no conflict of interest.

Ethical Approval The Institutional Review Board at Wonkwang University provided ethical approval for the research component of the OM-K program. All procedures performed in this study were in accordance with the ethical standards of the 1964 Helsinki declaration and its later amendments or comparable ethical standards.

Informed Consent Informed consent was obtained from the three preschools, the parents, and assent from the children.

Publisher's note: Springer Nature remains neutral with regard to jurisdictional claims in published maps and institutional affiliations.

Open Access This article is distributed under the terms of the Creative Commons Attribution 4.0 International License (http://crea tivecommons.org/licenses/by/4.0/), which permits unrestricted use, distribution, and reproduction in any medium, provided you give appropriate credit to the original author(s) and the source, provide a link to the Creative Commons license, and indicate if changes were made.

\section{References}

Blair, C., \& Diamond, A. (2008). Biological processes in prevention and intervention: the promotion of self-regulation as a means of preventing school failure. Development and Psychopathology, 20, 899-911. https://doi.org/10.1017/S0954579408000436.

Broderick, P. C. (2013). Learning to breathe: a mindfulness curriculum for adolescents to cultivate emotion regulation, attention, and performance. Oakland: New Harbinger Publications.

CASEL: Collaborative for Academic, Social, and Emotional Learning. (2015). Social and emotional learning core competencies. http://www.casel.org/social-and-emotional-learning/ corecompetencies/.

Durlak, J. A., Domitrovich, C. E., Weissberg, R. P., \& Gullotta, T. P. (2015). Handbook of social emotional learning: Research and practice. New York: Guilford Press.

Durlak, J. A., Weissberg, R. P., Dymnicki, A. B., Taylor, R. D., \& Schellinger, K. B. (2011). The impact of enhancing students' social and emotional learning: a meta-analysis of school-based universal interventions. Child Development, 82(1), 405-432.

Elias, M. J., \& Butler, L. B. (2005). Social decision making, social problem solving for middle school students: A curriculum for academic, social, and emotional learning. Champaign: Research Press.

Felver, J. C., Celis-de Hoyos, C. E., Tezanos, K., \& Singh, N. N. (2016). A systematic review of mindfulness-based interventions for youth in school settings. Mindfulness, 7(1), 34-45.

Feuerborn, L.L. \& Gueldner, B.A. (2019). Mindfulness and socialemotional competencies: proposing connections through a review of research. Mindfulness. Advance of Print. https://doi.org/10. 1007/s12671-019-01101-1.

Gerstein, E. D., Pedersen y Arbona, A., Crnic, K. A., Ryu, E., Baker, B. L., \& Blacher, J. (2011). Developmental risk and young children's regulatory strategies: predicting behavior problems at age five. Journal of Abnormal Child Psychology, 39, 351-364. https://doi.org/10.1007/s10802-010-9471-5.

Greenberg, M. T., Kusché, C. A., Cook, E. T., \& Quamma, J. P. (1995). Promoting emotional competence in school-aged children: the effects of the PATHS curriculum. Development and Psychopathology, 7(1), 117-136.

Gueldner, B. A., \& Feuerborn, L. L. (2016). Integrating mindfulnessbased practices into social and emotional learning: a case application. Mindfulness, 7(1), 164-175.

Hawn Foundation. (2011). The MindUp curriculum: brain-focused strategies for learning-and living. New York: Scholastic Teaching Resources. 
Hwang, Y.-S., Bartlett, B., Greben, M., \& Hand, K. (2017). A systematic review of mindfulness interventions for in-service teachers: a tool to enhance teacher wellbeing and performance. Teaching and Teacher Education, 64, 26-42.

Jackman, M. M. (2016). OpenMind-A mindfulness-based social emotional learning curriculum for Pre-K children: Daily practice Activities. Port St: Little Lotus Therapy and Consulting.

Jackman, M.M., Kim, E., Jo, S.-H., Oh, J., \& Ko, S.-Y. (2017). 오픈마인드 코리아: 유아를 위한 마음챙김 사회정서학습 교육과정 [OpenMind-Korea: A Mindfulness-based Social Emotional Learning Curriculum for Kindergarten Children]. Iksan: The Institute of Mind Humanities, Wonkwang University.

Kabat-Zinn, J. (2003). Mindfulness-based interventions in context: past, present and future. Clinical Psychology: Science and Practice, 10, 144-156.

Kam, C.-M., Greenberg, M. T., \& Kusché, C. A. (2004). Sustained effects of the PATHS curriculum on the social and psychological adjustment of children in special education. Journal of Emotional and Behavioral Disorders, 12, 66-78. https://doi.org/10.1177/ 10634266040120020101.

Klatt, M., Harpster, K., Browne, E., White, S., \& Case-Smith, J. (2013). Feasibility and preliminary outcomes for move-intolearning: an arts-based mindfulness classroom intervention. The Journal of Positive Psychology, 8(3), 233-241.

Lawlor, M. S 2016). Mindfulness and social emotional learning (SEL): a conceptual framework. In K. A. Schonert-Reichl, R. W. Roeser (Eds), Handbook of mindfulness in education (pp. 65-80). New York: Springer.

McClelland, M. M., Acock, A. C., Piccinin, A., Rhea, S. A., \& Stallings, M. C. (2012). Relations between preschool attention span persistence and age 25 educational outcomes. Early Childhood Research Quarterly, 28, 314-324. https://doi.org/10.1016/j. ecresq.2012.07.008.
McKeering, P., \& Hwang, Y.-S. (2019). A systematic review of mindfulness-based school interventions with early adolescents. Mindfulness, 10, 593-610.

Olson, S. L., Sameroff, A. J., Kerr, D. C. R., Lopez, N. L., \& Wellman, H. M. (2005). Developmental foundations of externalizing problems in young children: The role of effortful control. Development and Psychopathology, 17, 25-45. https://doi.org/10. 1017/S0954579405050029.

Pianta, R. C. \& Cox, M. J. (Eds) (1999). The transition to kindergarten. Baltimore: Paul H. Brookes.

Schonert-Reichl, K. A., \& Roeser, R. W. (2016). Handbook of mindfulness in education: Integrating theory and research into practice. New York: Springer.

Shonin, E., Van Gordon, W., \& Singh, N. N. (2015). Buddhist foundations of mindfulness. New York: Springer.

Sklad, M., Diekstra, R., Ritter, M. D., Ben, J., \& Gravesteijn, C. (2012). Effectiveness of school-based universal social, emotional, and behavioral programs: do they enhance students' development in the area of skill, behavior, and adjustment? Psychology in the Schools, 49(9), 892-909.

Stokols, D. (2006). Toward a science of transdisciplinary action research. American Journal of Community Psychology, 38(1-2), 79-93.

Taylor, R. D., Durlak, J. A., Oberle, E., \& Weissberg, R. P. (2017). Promoting positive youth development through school-based social and emotional learning interventions: a meta-analysis of follow-up effects. Child Development, 88(4), 1156-1171. https:// doi.org/10.1111/cdev.12864.

Zenner, C., Herrnleben-Kurz, S., \& Walach, H. (2014). Mindfulnessbased interventions in schools-a systematic review and metaanalysis. Frontiers in Psychology, 5, 603-603.

Zins, J. E., Weissberg, R. P., Wang, M. C., \& Walberg, H. J. (2004). Building academic success on social and emotional learning: What does the research say?. New York: Teachers College Press. 